\title{
Palmitate impairs angiogenesis via suppression of cathepsin activity
}

\author{
JIN ZHANG, YING SHAN, YONG LI, XINPING LUO and HAIMING SHI \\ Department of Cardiology, Huashan Hospital, Fudan University, Shanghai 200040, P.R. China
}

Received January 12, 2016; Accepted January 17, 2017

DOI: $10.3892 / \mathrm{mmr} .2017 .6463$

\begin{abstract}
Angiogenesis requires the interaction of multiple variable factors to promote endothelial cell adhesion, migration and survival. Palmitate, a free fatty acid, exhibits an anti-angiogenic effect via interference with endothelial cell function, whereas cysteine proteases are important in protein turnover and are termed positive modulators of neovascularization. However, the association between these two factors regarding the regulation of human endothelial cell function remains to be elucidated. By using cell counting kit-8, the Transwell method and an annexin V-fluorescein isothiocyanate/propidium iodide apoptosis detection kit, the present study reported that high levels of palmitate result in a significant decrease in endothelial cell proliferation and invasion, and induced cell apoptosis; cathepsin L and S inhibitors may suppress palmitate-induced apoptosis. Conversely, the results of the cathepsin $\mathrm{L}$ and $\mathrm{S}$ activity assay and reverse-transcription-quantitative polymerase chain reaction indicated that palmitate inhibited cathepsin-induced endothelial cell invasion, partially via suppressing the expression and activity of cathepsin L and S. The findings of the present study suggested that the potent anti-angiogenic properties of palmitate may be mediated by cysteine proteases.
\end{abstract}

\section{Introduction}

Angiogenesis is a complex multi-step process that occurs in response to ischemic stimuli. These steps include degradation of the basement membrane, proliferation, apoptosis and invasion of endothelial cells, tube formation, and anastomosis $(1,2)$. Various proteases including the family of matrix metalloproteinases (MMPs), and cysteine and serine proteases contribute to the complex processes of new vessel formation and remodeling. Urbich et al (3) demonstrated that cysteine

Correspondence to: Dr Haiming Shi, Department of Cardiology, Huashan Hospital, Fudan University, 12 Middle Urumqi Road, Shanghai 200040, P.R. China

E-mail: shihaiminghuashan@163.com

Key words: angiogenesis, endothelial cell, palmitate, cathepsin protease cathepsin L-deficient mice presented impaired wound recovery, indicating an important role for cathepsin $\mathrm{L}$ in neovascularization. Furthermore, the study validated the ability of cathepsin L to induce angiogenesis, as transferred cathepsin L-deficient progenitor cells did not migrate to ischemic areas or augment vasculogenesis. Conversely, forced expression of cathepsin L in mature endothelial cells markedly enhanced cell invasion. Furthermore, Shi et al (4) demonstrated that cathepsin $\mathrm{S}$ was required for microvessel formation. Cysteine proteases have previously been demonstrated to be important in apoptosis and cell survival, separate from their role in proteolysis of extracellular matrix in vascular remodeling (5-7); however, the underlying mechanism of this process remains to be fully elucidated.

Angiogenesis is associated with atherosclerosis, and numerous risk factors of atherosclerosis, including diabetes and insulin resistance, are accompanied by high levels of free fatty acids (FFA) $(8,9)$. However, the specific role of FFAs and their association with angiogenesis remains to be elucidated. FFAs have been demonstrated to exert effects on endothelial cells via enhancing reactive oxygen species levels or impairing nitric oxide production (10); therefore, increased levels of FFA will inhibit angiogenesis. Palmitate, which is the most frequently occurring form of saturated FFA present in human serum, contributes to lipotoxicity (11). In addition to the aforementioned characteristics, palmitate has been detected to induce apoptosis in a variety of tissues $(10,12,13)$ and decrease cardiolipid synthesis, resulting in the release of cytochrome c (14).

Cathepsin L and S have therefore been confirmed to be important in endothelial cell angiogenesis; however, it remains to be elucidated as to whether FFA levels may influence cathepsin-mediated angiogenesis. The present study examined the proliferation, apoptosis and invasion of human umbilical vein endothelial cells (HUVECs) following exposure to palmitate in the presence or absence of selective cathepsin inhibitors, and observed that palmitate impaired cathepsin protein expression levels and activity.

\section{Materials and methods}

Cell culture and incubation with fatty acids. HUVECs were purchased from the American Type Culture Collection (Manassas, VA, USA; PCS-100-010) and cultured in M199 medium (HyClone; GE Healthcare Life Sciences, 
Logan, UT, USA) supplemented with $20 \%$ fetal bovine serum (FBS; HyClone; GE Healthcare Life Sciences) at $37^{\circ} \mathrm{C}$ in an atmosphere containing under $5 \% \mathrm{CO}_{2}$. Cells were passaged every 2-3 days once they reached maximum confluence. Cells were incubated in M199/10\% FBS medium supplemented with $0.05,0.1,0.2,0.4$ or $0.6 \mathrm{mM}$ palmitate (Sigma-Aldrich; Merck KGaA, Darmstadt, Germany) preconjugated with FFA-free bovine serum albumin (BSA; Sigma-Aldrich; Merck KGaA) at a 1:1 molar ratio. Control cells were grown with the same medium containing FFA-free BSA. If not stated otherwise, cells were incubated for $1 \mathrm{~h}$ with $10 \mu \mathrm{M}$ cathepsin $\mathrm{L}$ inhibitor (z-FF-FMK; cat. no. 219421; Calbiochem; EMD Millipore, Billerica, MA, USA) and cathepsin S inhibitor (z-FL-COCHO. $\mathrm{H}_{2} \mathrm{O}$; cat. no. 219393; Calbiochem; EMD Millipore) at $37^{\circ} \mathrm{C}$, which was followed by incubation with palmitate or FFA-free BSA for $24 \mathrm{~h}$ at $37^{\circ} \mathrm{C}$.

Immunofluorescence staining. HUVECs were fixed in $4 \%$ paraformaldehyde for $20 \mathrm{~min}$ and incubated at $37^{\circ} \mathrm{C}$ in blocking buffer (PBS containing 5\% BSA). Cells were incubated in the presence of mouse anti-Cluster of Differentiation (CD) 31 antibody (1:200; cat. no. SC-81158; Santa Cruz Biotechnology, Inc., Dallas, TX, USA) for $2 \mathrm{~h}$ at $37^{\circ} \mathrm{C}$ and washed three times in PBS. Cells were subsequently incubated with rhodamine-conjugated goat anti-mouse IgG (H+L) secondary antibody (1:1,000; cat. no. 31660; Thermo Fisher Scientific, Inc., Waltham, MA, USA) for $1 \mathrm{~h}$ at $37^{\circ} \mathrm{C}$. Nuclei were stained with DAPI (1:10,000; Invitrogen; Thermo Fisher Scientific, Inc.) and were examined with an Olympus IX70 inverted fluorescence microscope.

Cell proliferation assay. The effect of elevated palmitate concentration on HUVEC proliferation was analyzed utilizing Cell Counting kit (CCK)-8 (Dojindo Molecular Technologies, Inc., Kumamoto, Japan) according to the manufacturer's protocol. The amount of the formazan dye generated in cells was directly proportional to the number of living cells. Absorbance of the samples was measured at a wavelength of $450 \mathrm{~nm}$.

Cell apoptosis assay. HUVECs were grown in M199 medium and pretreated for $1 \mathrm{~h}$ at $37^{\circ} \mathrm{C}$ with indicated protease inhibitors prior to the addition of $0,0.05,0.1,0.2,0.4$ or $0.6 \mathrm{mM}$ palmitate. Following palmitate treatment for $24 \mathrm{~h}$ at $37^{\circ} \mathrm{C}$, cells were harvested. A total of $1 \times 10^{6}$ cells were suspended in $200 \mu \mathrm{l}$ Annexin $\mathrm{V}$ binding buffer (BD Biosciences, Franklin Lakes, NJ, USA) and incubated with $2.5 \mu$ l annexin V-fluorescein isothiocyanate (FITC) and $2.5 \mu \mathrm{l}$ propidium iodide (PI; BD Biosciences) for $15 \mathrm{~min}$ at room temperature in the dark. Unstained cells and those stained with Annexin V-FITC or PI alone were used as controls to set up compensation and quadrants. Cell apoptosis was investigated by flow cytometry within $30 \mathrm{~min}$ after fluorescent labeling by using FlowJo ${ }^{\circledR}$ software (version 8.8.7; Tree Star, Inc., Ashland, OR, USA). Results were determined as the percentage of cells that were early (Annexin $\mathrm{V}^{+} \mathrm{PI}^{-}$) or late (Annexin $\mathrm{V}^{+} \mathrm{PI}^{+}$) apoptotic.

In vitro invasion. HUVEC invasion across a polycarbonate membrane containing $8-\mu \mathrm{m}$ pores was performed with
Transwell 24-well plates according to the manufacturer's protocol. Briefly, the membrane was precoated with type I collagen (1 mg/ml; Sigma-Aldrich; Merck KGaA). Detached cells $\left(1 \times 10^{5}\right.$ cells per $100 \mu \mathrm{l}$ in FBS-free M199 containing 0, $0.05,0.2,0.4$ and $0.6 \mathrm{mM}$ palmitate) were placed in the upper chambers. The lower chamber contained $600 \mu \mathrm{l}$ of M199 supplemented with $20 \%$ FBS and cells were incubated for $16 \mathrm{~h}$ at $37^{\circ} \mathrm{C}$. Following incubation, cells that remained on the upper surface of the membrane were removed by wiping with a cotton swab, while cells that crossed onto the lower side of the membrane were fixed with $4 \%$ paraformaldehyde for $30 \mathrm{~min}$ at room temperature and subsequently stained with crystal violet for $20 \mathrm{~min}$ at room temperature. The number of cells was counted manually in six random microscope fields by two independent investigators. The experiments were repeated in the presence of $10 \mu \mathrm{M}$ cathepsin inhibitors for $1 \mathrm{~h}$ prior to the addition of palmitate, as described above for cell culture.

Reverse transcription-quantitative polymerase chain reaction (RT-qPCR) analysis. Total RNA was extracted using TRIzol $^{\circledR}$ reagent (Sigma-Aldrich; Merck KGaA). cDNA was synthesized from $2 \mu \mathrm{g}$ total RNA using ReverTra Ace ${ }^{\circledR}$ qPCR Reverse Transcriptase kit (cat. no. FSQ-101; Toyobo Co., Ltd., Osaka, Japan) according to the manufacturer's protocol. qPCR was performed using the SYBR-Green Master mix (cat. no. QPK-212; Toyobo Co., Ltd.) in an ABI 7500HT Real-Time PCR machine (Applied Biosystems; Thermo Fisher Scientific, Inc.). The thermocycling conditions for PCR were $95^{\circ} \mathrm{C}$ for $60 \mathrm{sec}$, followed by 40 cycles at $95^{\circ} \mathrm{C}$ for $15 \mathrm{sec}$, $61^{\circ} \mathrm{C}$ for $15 \mathrm{sec}$ and $72^{\circ} \mathrm{C}$ for $45 \mathrm{sec}$. The relative expression level was determined by the $2^{-\Delta \Delta \mathrm{Cq}}$ method and normalized against GAPDH (15). The primer sequences used were as follows: Forward, 5'-CGAATCATTGAAGATCCGAGTG-3' and reverse, 5'-ATGGCTTAGAGCCCAATTATGT-3' for cathepsin L; forward, 5-TATTGCCTGATTCTGTGGACT G-3 and reverse, 5-TGATGTACTGGAAAGCCGTTGT-3 for cathepsin S; forward, 5'-GCAGATCGTAGCTGGGGTGAA CT-3' and reverse, 5'-AAGCAAGAAGGAAGGAGGGAG GG-3' for cystatin C; and forward, 5'-TGCACCACCAAC TGCTTAGC-3' and reverse, 5'-GGCATGGACTGTGGTCAT GAG-3' for GAPDH.

Western blot analysis. Cells were lysed in ice-cold radioimmunoprecipitation assay buffer (Sigma-Aldrich; Merck $\mathrm{KGaA}$ ) supplemented with $1 \mathrm{mM}$ phenomethylsulfonyl fluoride (Thermo Fisher Scientific, Inc.). The proteins $(20 \mu \mathrm{g}$ per lane) were separated on a $12 \%$ SDS-PAGE gel (Bio-Rad Laboratories, Inc., Hercules, CA, USA) and electrotransferred onto a polyvinylidene difluoride membrane. Following transfer, blocking was performed with 5\% BSA (Sigma-Aldrich; Merck $\mathrm{KGaA}$ ) for $1 \mathrm{~h}$ at room temperature. Membranes were probed with specific primary antibodies at $4^{\circ} \mathrm{C}$ overnight and horseradish peroxidase (HRP)-conjugated anti-rabbit/ mouse immunoglobulin secondary antibodies (1:5,000; cat. nos. SC-2004 and SC-2005; Santa Cruz Biotechnology, Inc.) for $1 \mathrm{~h}$ at room temperature. The primary antibodies used were mouse anti-cathepsin L (1:1,000; cat. no. ab6314; Abcam, Cambridge, UK), rabbit anti-cathepsin S (1:5,000; cat. no. ab50400; Abcam), rabbit anti-cystatin C (1:500; cat. 
A

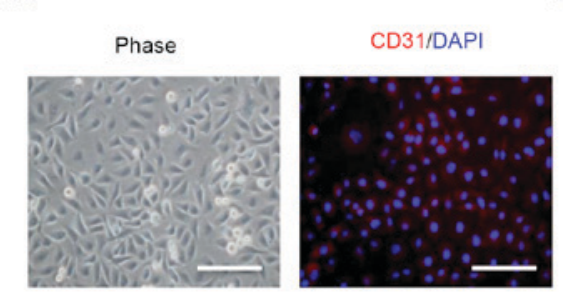

C

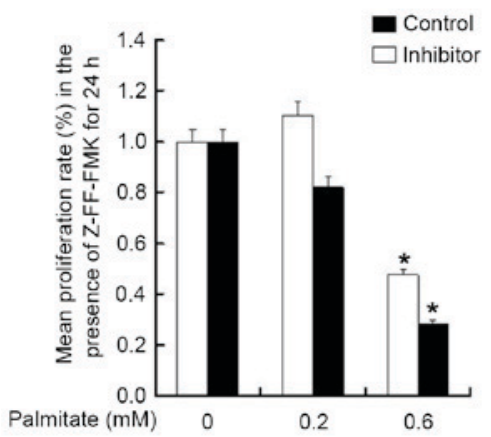

B

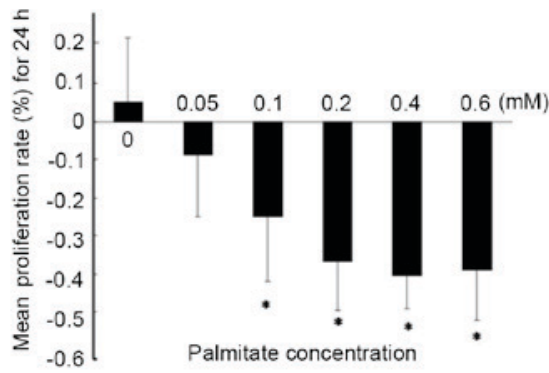

D

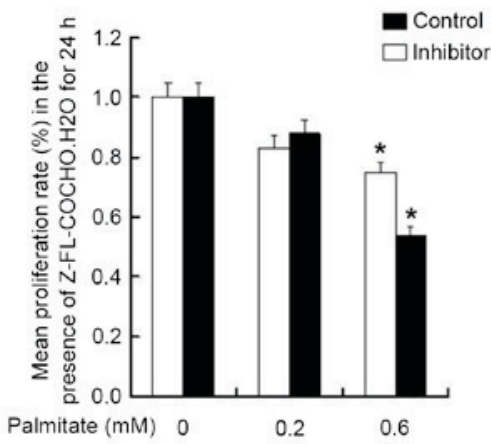

Figure 1. Effect of palmitate and cathepsin inhibitors on cell proliferation. (A) Identification of human umbilical vein endothelial cells using fluorescence microscopy. Cells were treated with an anti-CD31 antibody for $2 \mathrm{~h}$ followed by a rhodamine-conjugated secondary antibody, indicated in red. Nuclei were stained with DAPI, indicated in blue. Scale bar=100 $\mu \mathrm{M}$. (B) Cells were suspended in M199/fetal bovine serum medium supplemented with Cell Counting kit- 8 solution. Absorbance values were determined at a wavelength of $450 \mathrm{~nm}$. Cells were treated with specific cathepsin inhibitors against (C) cathepsin L and (D) cathepsin $\mathrm{S}$ for $1 \mathrm{~h}$ prior to exposure to palmitate for $24 \mathrm{~h}$. Data are expressed as the mean \pm standard deviation from triplicate experiments. ${ }^{*}<0.001$ vs. $0 \mathrm{mM}$. CD, cluster of differentiation.

no. ab33487; Abcam) and mouse anti-tubulin (1:1,000; cat. no. AT819; Beyotime Institute of Biotechnology, Haimen, China). Enhanced chemiluminescence was performed using the Pro-light HRP Chemiluminescence kit according to the instructions of the manufacturer (Tiangen Biotech Co., Ltd., Beijing, China). Membranes were scanned and visualized by an LAS3000 system (LAS3000 mini ImageReader, Fuji Photo Film Co., Ltd., Japan).

Cathepsins L and $S$ activity assay. Cells were lysed and treated with reaction buffer that was included in the kits used for cathepsin L (cat. no. ab65306; Abcam) or cathepsin S (cat. no. ab65307; Abcam), and $10 \mathrm{mM}$ fluorogenic Ac-FR-amino-4-trifluoromethyl coumarin (AFC) substrate, which is the preferred cathepsin L substrate (cat. no. ab65306; Abcam) or $10 \mathrm{mM}$ Ac-VVR-AFC, which is the preferred cathepsin S substrate (cat. no. ab65307; Abcam) according to the manufacturer's protocol. Fluorescence was measured using SpectraMax M5 fluorometer, at an excitation wavelength of $400 \mathrm{~nm}$ and an emission wavelength of $505 \mathrm{~nm}$.

Statistical analysis. Data are expressed as the mean \pm standard deviation of at least three independent experiments. Multiple group comparisons were performed by one-way analysis of variance followed by the least significant difference post hoc test. All tests analyzed were two-sided. $\mathrm{P}<0.05$ was considered to indicate a statistically significant difference. All statistical analyses were conducted using SPSS software version 11.5 (SPSS, Inc., Chicago, IL, USA).

\section{Results}

Effect of palmitate and cysteine protease on HUVEC proliferation. HUVECs express the endothelial marker protein CD31 as previously described (16), and as presented in Fig. 1A. To examine the effect of palmitate on HUVEC proliferation, HUVECs were incubated with different concentrations of palmitate and it was observed that palmitate decreased HUVEC proliferation in a dose-dependent manner (Fig. 1B). High levels of palmitate $(0.6 \mathrm{mM})$ inhibited the proliferation rate significantly by $44 \pm 7 \%$ ( $\mathrm{P}<0.05$ vs. $0 \mathrm{mM})$, whereas the lowest concentration $(0.05 \mathrm{mM})$ had no significant effect $(\mathrm{P}=0.09$ vs. $0 \mathrm{mM}$ ). These results are consistent with a previous report (17). To determine whether cathepsin is associated with HUVEC proliferation in the presence of a high concentration of FFA, cysteine protease inhibitors were added to the concentrations of palmitate. It was observed that treatment with the cathepsin L inhibitor Z-FF-FMK (Fig. 1C) and the cathepsin S inhibitor Z-FL-COCHO (Fig. 1D) did not result in significant alterations of the growth rate $(\mathrm{P}>0.05)$, suggesting palmitate reduced HUVEC proliferation via a cathepsin-independent pathway.

Cysteine protease inhibitors attenuate palmitate-induced HUVEC apoptosis. Palmitate may trigger apoptotic pathways in HUVECs (17); therefore, the present study examined whether cathepsin regulated palmitate-induced HUVEC apoptosis (Fig. 2A). As presented in Fig. 2B, cathepsin L and $\mathrm{S}$ inhibitors exhibited the ability to reduce the early apoptosis of HUVECs induced by palmitate by almost $50 \%$, suggesting a key cathepsin-dependent pathway in 
A
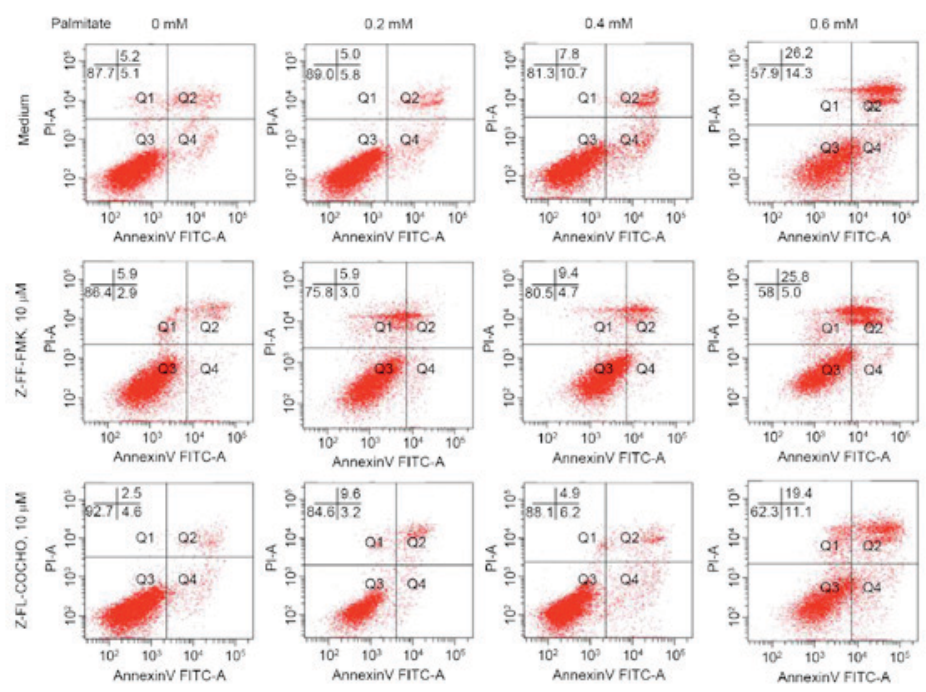

B

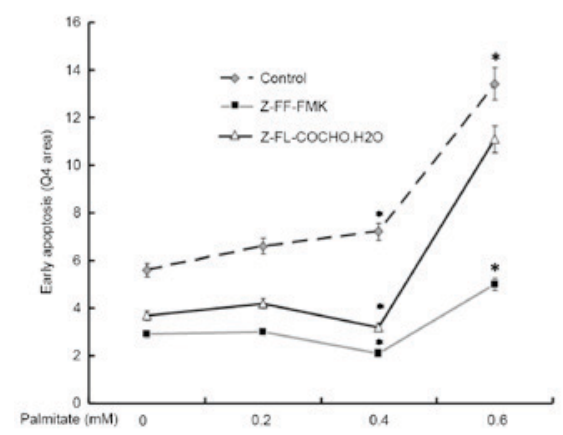

C

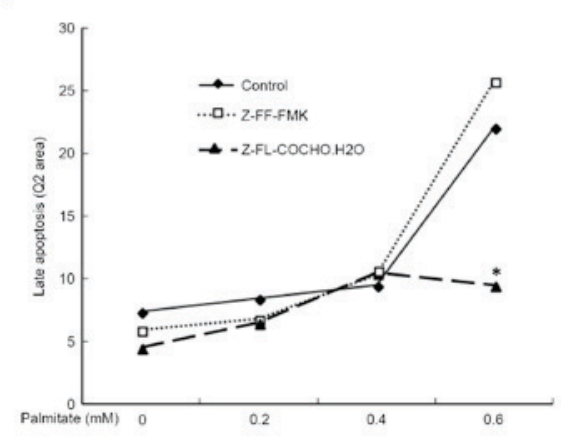

Figure 2. Effect of palmitate and cathepsin inhibitors on cell apoptosis. Cell apoptosis was analyzed by flow cytometry. (A) A total of $1 \times 10^{6}$ cells suspended in $200 \mu \mathrm{l}$ binding buffer containing $2.5 \mu \mathrm{l}$ annexin V-FITC and $2.5 \mu 1$ PI were analyzed following incubation in the dark. Percentage of cells in (B) early (lower right quadrant, Annexin $\mathrm{V}^{+} \mathrm{PI}^{-}$) and (C) late (upper right quandrant, annexin $\mathrm{V}^{+} \mathrm{PI}^{+}$) apoptotic stages. Three separate experiments were performed. Data are expressed as the mean \pm standard deviation. ${ }^{*} \mathrm{P}<0.05$ vs. $0 \mathrm{mM}$. FITC, fluorescein isothiocyanate; PI, propidium iodide.

A

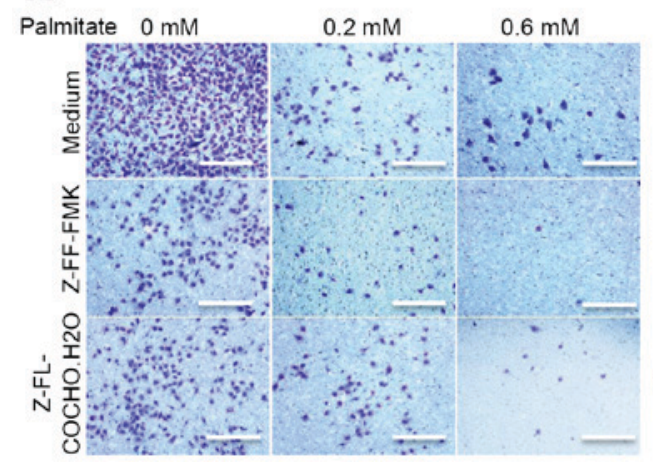

$\mathbf{B}$

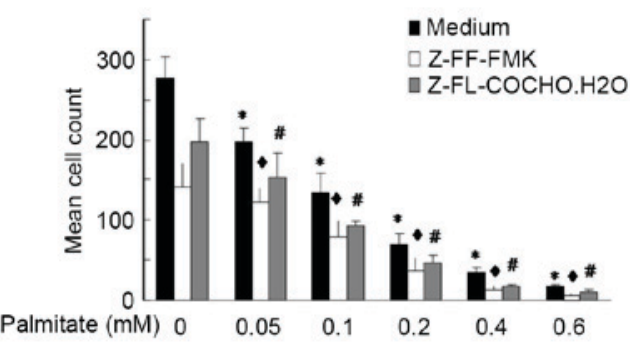

Figure 3. Effect of palmitate and cathepsin inhibitors on cell invasion. (A) Images represent alteration of cell invasion as assessed by a Transwell assay. Scale bar $=100 \mu \mathrm{M}$. (B) Analysis of Transwell assay data. Data are expressed as the mean \pm standard deviation from at least three separate experiments. ${ }^{*} \mathrm{P}<0.05 \mathrm{vs.}$ $0 \mathrm{mM}$ palmitate+medium; ${ }^{\circ} \mathrm{P}<0.05$ vs. $0 \mathrm{mM}$ palmitate+Z-FF-FMK; ${ }^{*} \mathrm{P}<0.05$ vs. $0 \mathrm{mM}$ palmitate+Z-FL-COCHO. $\mathrm{H}_{2} \mathrm{O}$.

palmitate-induced apoptosis. Furthermore, cathepsin L inhibitor Z-FF-FMK exhibited the ability to reduce early apoptosis more effectively compared with the cathepsin $\mathrm{S}$ inhibitor Z-FL-COCHO. However, late apoptosis appeared to be unaffected by cathepsin inhibitors (Fig. 2C). These results suggested that cathepsin $\mathrm{L}$ and $\mathrm{S}$ are associated with cell apoptosis as the cathepsin inhibitors protected cells from high FFA level-induced apoptosis.
Palmitate inhibits cathepsin-mediated cell invasion. Previous reports have demonstrated that cathepsin $\mathrm{L}$ is required for endothelial progenitor cell invasion and neovascularization $(3,18)$; however, whether other cathepsins may influence cell invasion and whether the effects of decreased invasion result from increased FFA levels remains to be elucidated. The present study firstly assessed the effect of palmitate on cell invasion ability using a Transwell assay. It was observed 
A

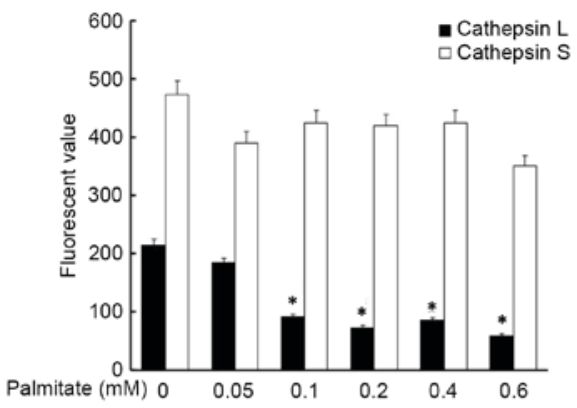

B
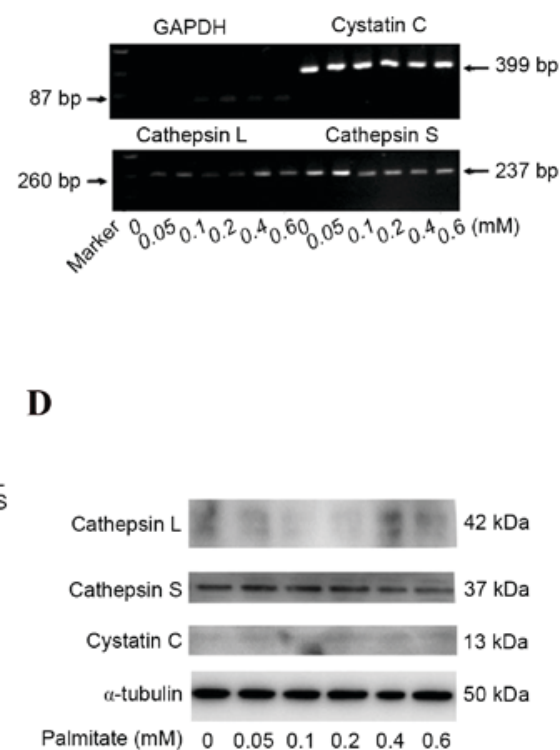

D

$\begin{array}{lllllll}\text { Palmitate }(\mathrm{mM}) & 0 & 0.05 & 0.1 & 0.2 & 0.4 & 0.6\end{array}$
C

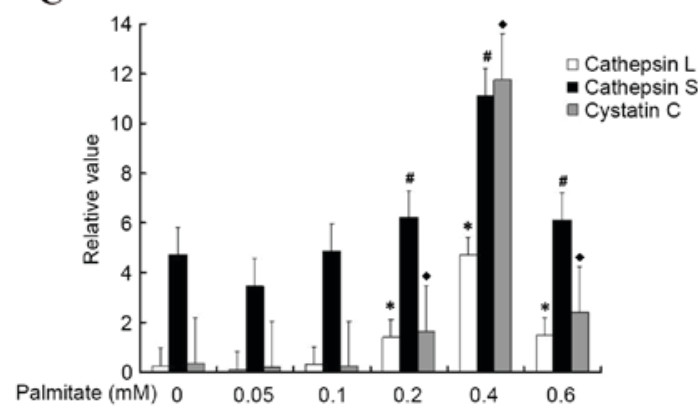

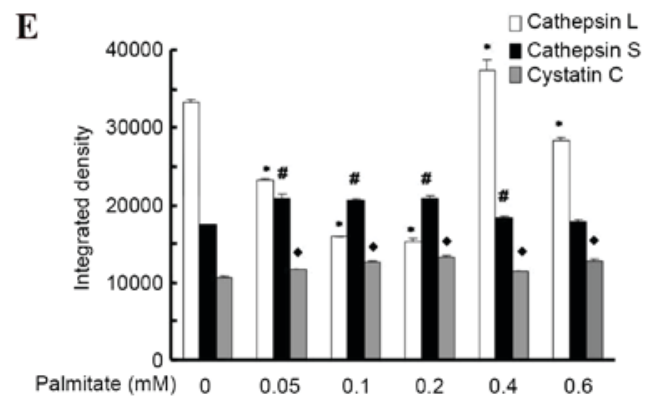

Figure 4. Inhibition of cathepsins S and L by palmitate. (A) Cell lysates were incubated with the fluorogenic substrate detecting cathepsin L or S activity. Fluorescence was measured at an excitation wavelength of $400 \mathrm{~nm}$ and an emission wavelength of $505 \mathrm{~nm}$. "P<0.05 vs. 0 mM. Cathepsin L and S and cystatin $\mathrm{C}$ mRNA expression levels were (B) detected and (C) quantified using reverse transcription-quantitative polymerase chain reaction. Cathepsin $\mathrm{L}$ and $\mathrm{S}$ and cystatin C protein expression levels were (D) detected and (E) quantified using western blot. Tubulin served as loading control. Blots are representative of at least 3 independent experiments. Data are presented as the mean \pm standard deviation from triplicate experiments. ${ }^{*} \mathrm{P}<0.05$ vs. $0 \mathrm{mM}$ palmitate, cathepsin $\mathrm{L}$; ${ }^{\#} \mathrm{P}<0.05$ vs. $0 \mathrm{mM}$ palmitate, cathepsin $\mathrm{S} ;{ }^{\bullet} \mathrm{P}<0.05$ vs. $0 \mathrm{mM}$ palmitate, cystatin $\mathrm{C}$.

that 0.4 and $0.6 \mathrm{mM}$ palmitate reduced endothelial cell invasion by 88 and $94 \%$, respectively, compared with untreated cells (Fig. 3), indicating that palmitate inhibits cell invasion in a dose-dependent manner. Furthermore, cathepsin S and L inhibitors significantly reduced the cell migration by almost 2 -fold, even in the presence of a high level of palmitate (Fig. 3). These findings indicated that cathepsins contribute to cell migration and invasion and palmitate is a potential factor that may reduce cathepsin-mediated cell invasion.

Palmitate suppresses the activity of cathepsins $L$ and $S$. To investigate the underlying mechanism of cathepsins $\mathrm{L}$ and $\mathrm{S}$ reduction in response to high FFA levels, the present study measured the effect of high palmitate levels on the mRNA and protein expression levels, and activities of cathepsin $\mathrm{L}$ and $\mathrm{S}$ in HUVECs. The protease activity experiment demonstrated that cells incubated in palmitate for $24 \mathrm{~h}$ presented a markedly attenuated cathepsin L activity $(\mathrm{P}<0.05$; Fig. $4 \mathrm{~A})$ compared with those cells cultured in medium without palmitate. The greatest palmitate level decreased the activity of cathepsin L by almost 3.6 fold (Fig. 4A). In addition, the high palmitate level attenuated cathepsin S activity; however, this alteration was not significant (Fig. 4A). To further analyze the effect of high palmitate levels on protease expression, the present study detected the mRNA expression levels of cathepsin L, S and their natural inhibitor cystatin $\mathrm{C}$, and observed that palmitate an increased expression levels in a dose-dependent manner (Fig. 4B and C), suggesting a regulatory interaction between palmitate and cathepsins or their endogenous inhibitor. Consistent with the mRNA expression, cathepsin L protein level was upregulated by high palmitate levels at $0.4 \mathrm{mM}$ but was downregulated by $0.6 \mathrm{mM}$ palmitate (Fig. 4D and E), thus, high palmitate levels $(>0.4 \mathrm{mM})$ may have a role in inhibiting cathepsin L activity. However, the protein expression levels of cathepsin S and cystatin C appeared to vary only slightly with different palmitate concentrations, the differences between the mRNA and protein results may be a result of posttranscriptional modifications. 


\section{Discussion}

The present study demonstrated that exposure of cultured HUVECs to palmitate led to impairment of cell proliferation and invasion, and increased cell apoptosis, and that the function of palmitate is associated with cathepsin L and S. Further experiments demonstrated that palmitate inhibited the activity of cathepsin L and S in HUVECs.

The effects of FFA on cell proliferation, apoptosis and invasion have previously been investigated; Listenberger et al (10) observed that saturated fatty acids increase nicotinamide adenine dinucleotide phosphate oxidase-generated oxidant stress, nuclear factor-kB activation and ceramide accumulation. The latter, which may be synthesized de novo from saturated fatty acids and the amino acid serine, has been implicated in apoptosis and oxidative stress modulation (19-21). Consistent with these reports, high concentrations of saturated fatty acids may trigger apoptosis and inhibit cell cycle progression in cultured human endothelial cell monolayers (22-24). In addition, trophoblast cells treated with long-chain fatty acids revealed increased lipid droplet deposition, severe mitochondrial damage and significantly decreased invasion (25). The present study demonstrated that the FFA palmitate exhibits similar effects on HUVECs.

Cysteine proteases contribute to angiogenesis under pathophysiological conditions. Cathepsins were originally identified as members of the cysteine protease family localized in lysosomes. However, previous data revealed unexpected roles for cathepsins in pathological conditions including cell survival, metabolic disorder and atherosclerosis-based cardiovascular disease (26-31). However, the definite underlying molecular mechanism remains to be fully elucidated. A variety of cathepsins (B, D, L, S and K) have been demonstrated to cleave the pro-apoptotic B-cell lymphoma-2 (Bcl-2) family member BH3 interacting domain death agonist (Bid) into its potent pro-apoptotic tBid fragment in vitro $(32,33)$. Translocation of these pro-apoptotic fragments to the mitochondrial outer membrane may induce the release of apoptogenic factors including cytochrome $\mathrm{c}$ and subsequent activation of downstream caspases. In addition to Bcl-2 family members, caspases may be appropriate candidates as cathepsin substrates (34-39). It was therefore hypothesized that cysteine proteases contribute to the regulation of apoptotic signaling mechanisms. Consistent with this, the present study observed that cathepsin inhibitors protected cells from high FFA level-induced apoptosis. In addition, it has previously been demonstrated that intracellular and extracellular cathepsin S, L and $\mathrm{K}$ activities were reduced in non-invasive compared with highly invasive cells (40), and downregulation of cathepsins $\mathrm{L}$ and $\mathrm{S}$ led to defective endothelial cell invasion and suppression of proliferation $(41,42)$, indicating that cathepsins are important for angiogenesis. Therefore, cathepsins $\mathrm{S}$ and $\mathrm{L}$ are required for endothelial progenitor cell-induced neovascularization in response to ischemic stress $(3,43)$.

In conclusion, the results of the present study, in conjunction with previous findings, support the anti-angiogenic action of FFA. The results suggested that the cathepsin-dependent effects should be considered when developing novel therapies during human endothelial cell angiogenesis. These findings suggested a novel approach to pharmacological and genetic rescue strategies in FFA-mediated angiogenesis.

\section{Acknowledgements}

The present study was funded by the National Natural Science Foundation of China (grant nos. 81300167 and 30873350).

\section{References}

1. Binet F and Sapieha P: ER stress and angiogenesis. Cell Metab 22: $560-575,2015$

2. Pourrajab F, Vakili Zarch A, Hekmatimoghaddam S and Zare-Khormizi MR: MicroRNAs; easy and potent targets in optimizing therapeutic methods in reparative angiogenesis. J Cell Mol Med 19: 2702-2714, 2015.

3. Urbich C, Heeschen C, Aicher A, Sasaki K, Bruhl T, Farhadi MR, Vajkoczy P, Hofmann WK, Peters C, Pennacchio LA, et al: Cathepsin $\mathrm{L}$ is required for endothelial progenitor cell-induced neovascularization. Nat Med 11: 206-213, 2005.

4. Shi GP, Sukhova GK, Kuzuya M, Ye Q, Du J, Zhang Y, Pan JH, $\mathrm{Lu}$ ML, Cheng XW, Iguchi A, et al: Deficiency of the cysteine protease cathepsin S impairs microvessel growth. Circ Res 92: 493-500, 2003

5. Conus S and Simon HU: Cathepsins: Key modulators of cell death and inflammatory responses. Biochem Pharmacol 76: 1374-1382, 2008.

6. Droga-Mazovec G, Bojic L, Petelin A, Ivanova S, Romih R, Repnik U, Salvesen GS, Stoka V, Turk V and Turk B: Cysteine cathepsins trigger caspase-dependent cell death through cleavage of bid and antiapoptotic Bcl-2 homologues. J Biol Chem 283: 19140-19150, 2008.

7. Zheng X, Chu F, Mirkin BL, Sudha T, Mousa SA and Rebbaa A: Role of the proteolytic hierarchy between cathepsin L, cathepsin D and caspase-3 in regulation of cellular susceptibility to apoptosis and autophagy. Biochim Biophys Acta 1783: 2294-2300, 2008.

8. Shulman GI: Cellular mechanisms of insulin resistance. J Clin Invest 106: 171-176, 2000.

9. Boden G and Shulman GI: Free fatty acids in obesity and type 2 diabetes: Defining their role in the development of insulin resistance and beta-cell dysfunction. Eur J Clin Invest 32 (Suppl 3): S14-S23, 2002.

10. Listenberger LL, Ory DS and Schaffer JE: Palmitate-induced apoptosis can occur through a ceramide-independent pathway. J Biol Chem 276: 14890-14895, 2001.

11. Listenberger LL, Han X, Lewis SE, Cases S, Farese RV Jr, Ory DS and Schaffer JE: Triglyceride accumulation protects against fatty acid-induced lipotoxicity. Proc Natl Acad Sci USA 100: 3077-3082, 2003.

12. Paumen MB, Ishida $Y$, Muramatsu M, Yamamoto $M$ and Honjo T: Inhibition of carnitine palmitoyltransferase I augments sphingolipid synthesis and palmitate-induced apoptosis. J Biol Chem 272: 3324-3329, 1997.

13. Cnop M, Hannaert JC, Hoorens A, Eizirik DL and Pipeleers DG: Inverse relationship between cytotoxicity of free fatty acids in pancreatic islet cells and cellular triglyceride accumulation. Diabetes 50: 1771-1777, 2001

14. Ostrander DB, Sparagna GC, Amoscato AA, McMillin JB and Dowhan W: Decreased cardiolipin synthesis corresponds with cytochrome c release in palmitate-induced cardiomyocyte apoptosis. J Biol Chem 276: 38061-38067, 2001.

15. Livak KJ and Schmittgen TD: Analysis of relative gene expression data using real-time quantitative PCR and the 2(-Delta Delta C(T)) Method. Methods 25: 402-408, 2001.

16. Pinter E, Mahooti S, Wang Y, Imhof BA and Madri JA: Hyperglycemia-induced vasculopathy in the murine vitelline vasculature: Correlation with PECAM-1/CD31 tyrosine phosphorylation state. Am J Pathol 154: 1367-1379, 1999.

17. Ciapaite J, van Bezu J, van Eikenhorst G, Bakker SJ, Teerlink T, Diamant M, Heine RJ, Krab K, Westerhoff HV and Schalkwijk CG: Palmitate and oleate have distinct effects on the inflammatory phenotype of human endothelial cells. Biochim Biophys Acta 1771: 147-154, 2007.

18. Urbich C, Dernbach E, Rössig L, Zeiher AM and Dimmeler S: High glucose reduces cathepsin L activity and impairs invasion of circulating progenitor cells. J Mol Cell Cardiol 45: 429-436, 2008. 
19. Shimabukuro M, Zhou YT, Levi $M$ and Unger RH: Fatty acid-induced beta cell apoptosis: A link between obesity and diabetes. Proc Natl Acad Sci USA 95: 2498-2502, 1998.

20. Chiu HC, Kovacs A, Ford DA, Hsu FF, Garcia R, Herrero P, Saffitz JE and Schaffer JE: A novel mouse model of lipotoxic cardiomyopathy. J Clin Invest 107: 813-822, 2001.

21. Gudz TI, Tserng KY and Hoppel CL: Direct inhibition of mitochondrial respiratory chain complex III by cell-permeable ceramide. J Biol Chem 272: 24154-24158, 1997.

22. Vafeiadou K, Weech M, Sharma V, Yaqoob P, Todd S, Williams CM, Jackson KG and Lovegrove JA: A review of the evidence for the effects of total dietary fat, saturated, monounsaturated and n- 6 polyunsaturated fatty acids on vascular function, endothelial progenitor cells and microparticles. Br J Nutr 107: 303-324, 2012

23. Zhang CL, Lyngmo V and Nordøy A: The effects of saturated fatty acids on endothelial cells. Thromb Res 65: 65-75, 1992.

24. Artwohl M, Roden M, Waldhäusl W, Freudenthaler A and Baumgartner-Parzer SM: Free fatty acids trigger apoptosis and inhibit cell cycle progression in human vascular endothelial cells. FASEB J 18: 146-148, 2004.

25. Yu H, Yang Z, Ding X, Wang Y and Han Y: Correlation between the different chain lengths of free fatty acid oxidation and ability of trophoblastic invasion. Chin Med J (Engl) 127: 3378-3382, 2014.

26. Dimmeler S, Haendeler J, Galle J and Zeiher AM: Oxidized low-density lipoprotein induces apoptosis of human endothelial cells by activation of CPP32-like proteases. A mechanistic clue to the 'response to injury' hypothesis. Circulation 95: 1760-1763, 1997.

27. Sata M and Walsh K: Oxidized LDL activates fas-mediated endothelial cell apoptosis. J Clin Invest 102: 1682-1689, 1998.

28. Raymond MA, Désormeaux A, Laplante P, Vigneault N, Filep JG, Landry K, Pshezhetsky AV and Hébert MJ: Apoptosis of endothelial cells triggers a caspase-dependent anti-apoptotic paracrine loop active on VSMC. FASEB J 18: 705-707, 2004.

29. Laplante $P$, Raymond MA, Gagnon G, Vigneault $N$ Sasseville AM, Langelier Y, Bernard M, Raymond Y and Hébert MJ: Novel fibrogenic pathways are activated in response to endothelial apoptosis: Implications in the pathophysiology of systemic sclerosis. J Immunol 174: 5740-5749, 2005.

30. Li D, Yang B and Mehta JL: Ox-LDL induces apoptosis in human coronary artery endothelial cells: Role of PKC, PTK, bcl-2, and Fas. Am J Physiol 275: H568-H576, 1998.

31. Choy JC, Granville DJ, Hunt DW and McManus BM: Endothelial cell apoptosis: Biochemical characteristics and potential implications for atherosclerosis. J Mol Cell Cardiol 33: 1673-1690, 2001.

32. Cirman T, Oresić K, Mazovec GD, Turk V, Reed JC, Myers RM, Salvesen GS and Turk B: Selective disruption of lysosomes in $\mathrm{HeLa}$ cells triggers apoptosis mediated by cleavage of Bid by multiple papain-like lysosomal cathepsins. J Biol Chem 279: 3578-3587, 2004
33. Heinrich M, Neumeyer J, Jakob M, Hallas C, Tchikov V, Winoto-Morbach S, Wickel M, Schneider-Brachert W, Trauzold A, Hethke A and Schütze S: Cathepsin D links TNF-induced acid sphingomyelinase to Bid-mediated caspase-9 and -3 activation. Cell Death Differ 11: 550-563, 2004.

34. Stoka V, Turk B, Schendel SL, Kim TH, Cirman T, Snipas SJ, Ellerby LM, Bredesen D, Freeze H, Abrahamson M, et al: Lysosomal protease pathways to apoptosis. Cleavage of bid, not pro-caspases, is the most likely route. J Biol Chem 276: 3149-3157, 2001.

35. Guicciardi ME, Leist M and Gores GJ: Lysosomes in cell death. Oncogene 23: 2881-2890, 2004

36. Schotte P, Van Criekinge W, Van de Craen M, Van Loo G, Desmedt M, Grooten J, Cornelissen M, De Ridder L, Vandekerckhove J, Fiers W, et al: Cathepsin B-mediated activation of the proinflammatory caspase-11. Biochem Biophys Res Commun 251: 379-387, 1998

37. Vancompernolle K, Van Herreweghe F, Pynaert G, Van de Craen M, De Vos K, Totty N, Sterling A, Fiers W, Vandenabeele P and Grooten J: Atractyloside-induced release of cathepsin B, a protease with caspase-processing activity. FEBS Lett 438: $150-158,1998$

38. Ishisaka R, Utsumi T, Kanno T, Arita K, Katunuma N, Akiyama J and Utsumi K: Participation of a cathepsin L-type protease in the activation of caspase-3. Cell Struct Funct 24: 465-470, 1999.

39. Ishisaka R, Kanno T, Akiyama J, Yoshioka T, Utsumi K and Utsumi T: Activation of caspase-3 by lysosomal cysteine proteases and its role in 2,2'-azobis-(2-amidinopropane) dihydrochloride (AAPH)-induced apoptosis in HL-60 cells. J Biochem 129: 35-41, 2001.

40. Tsai JY, Lee MJ, Dah-Tsyr Chang M and Huang H: The effect of catalase on migration and invasion of lung cancer cells by regulating the activities of cathepsin S, L, and K. Exp Cell Res 323: 28-40, 2014.

41. Zhang Q, Han M, Wang W, Song Y, Chen G, Wang Z and Liang Z: Downregulation of cathepsin $L$ suppresses cancer invasion and migration by inhibiting transforming growth factor- $\beta$-mediated epithelial-mesenchymal transition. Oncol Rep 33: 1851-1859, 2015.

42. Burden RE, Gormley JA, Jaquin TJ, Small DM, Quinn DJ, Hegarty SM, Ward C, Walker B, Johnston JA, Olwill SA and Scott CJ: Antibody-mediated inhibition of cathepsin S blocks colorectal tumor invasion and angiogenesis. Clin Cancer Res 15: 6042-6051, 2009

43. Li X, Cheng XW, Hu L, Wu H, Guo-Ping, Hao CN, Jiang H, Zhu E, Huang Z, Inoue A, et al: Cathepsin S activity controls ischemia-induced neovascularization in mice. Int J Cardiol 183: 198-208, 2015. 